\title{
Review \\ Comparative Review of Malignant Melanoma and Histologically Well-Differentiated Melanocytic Neoplasm in the Oral Cavity of Dogs
}

\author{
Won Suk Kim ${ }^{1, *}$, Arathi Vinayak ${ }^{1}$ and Barbara Powers ${ }^{2}$ \\ 1 Department of Surgical Oncology, VCA West Coast Specialty and Emergency Animal Hospital, \\ 18300 Euclid Street, Fountain Valley, CA 92708, USA; arathi.vinayak@vca.com \\ 2 Antech Diagnostics, 17620 Mt Hermann St, Fountain Valley, CA 92708, USA; barbara.powers@antechmail.com \\ * Correspondence: wonkim846@gmail.com
}

\section{check for}

updates

Citation: Kim, W.S.; Vinayak, A.; Powers, B. Comparative Review of Malignant Melanoma and Histologically Well-Differentiated Melanocytic Neoplasm in the Oral Cavity of Dogs. Vet. Sci. 2021, 8, 261. https://doi.org/10.3390/ vetsci8110261

Academic Editors: Louise van der Weyden and Kelly Lisa Bowlt Blacklock

Received: 1 October 2021

Accepted: 27 October 2021

Published: 2 November 2021

Publisher's Note: MDPI stays neutral with regard to jurisdictional claims in published maps and institutional affiliations.

Copyright: (c) 2021 by the authors. Licensee MDPI, Basel, Switzerland. This article is an open access article distributed under the terms and conditions of the Creative Commons Attribution (CC BY) license (https:// creativecommons.org/licenses/by/ $4.0 /)$.

\begin{abstract}
Oral malignant melanoma (OMM) is the most common neoplasm of the canine oral cavity. It is characterized by its aggressive local disease as well as its high rate of lymphatic invasion and distant metastasis. OMM carries a poor prognosis, with most patients succumbing to the disease due to progression of the neoplasm. Histopathologically, OMM is characterized by significant nuclear atypia, a mitotic index of greater than $4 / 10 \mathrm{hpf}$, and evidence of vascular invasion or metastasis. Clinically, these lesions can become locally invasive, causing lysis of bones and severe inflammation of the surrounding soft tissue. With time, these lesions can spread to the regional lymph node and to the lungs and other organs. Prognosis can vary depending on the size of the primary tumor, regional node involvement, and distant metastatic disease; however, multiple studies report a relatively short median survival time ranging from less than 4 months to 8 months. Histologically well- differentiated melanocytic neoplasms (HWDMN) are a variant of OMM and sometimes referred to as canine oral melanocytic neoplasms of low malignant potential. Unlike OMM, patients with HWDMN have longer survival times. Histopathologically, HWDMNs have well-differentiated melanocytes with a low mitotic index of 3 or less per $10 \mathrm{hpf}$ and minimal nuclear atypia. HWDMNs have better prognosis with a mean survival time of up to 34 months. This article is a comparative review of OMM and its less aggressive counterpart.
\end{abstract}

Keywords: oral tumor; melanoma; melanocytic neoplasm; mitotic index

\section{Introduction}

Canine oral malignant melanoma (OMM) is an aggressive cancer of the oral cavity in dogs that accounts for $11.5 \%$ [1] to $17.1 \%$ [2] of all oral tumors and is the most common malignant oral tumor, making up between 33\% [3]-35.8\% [1] of all malignant oral tumors. This devastating cancer is characterized by its marked local destruction as well as a high propensity to metastasize [3-6]. Prognosis with OMM is poor, with a reported median survival time (MST) of 65 days without treatment [7]. The primary treatment of OMM is wide-margin surgical resection [8] with adjuvant treatments such as intensity-modulated radiation therapy (IMRT), considered if margins are narrow/incomplete, or coarse fraction radiation, considered as the sole treatment from a palliative standpoint $[9,10]$. The staging of OMM is based on the World Health Organization (WHO) staging scheme and is dependent on the tumor size and regional and distant metastatic disease [11]. The overall reported MST following surgical excision vary depending on the stage of disease; Stage I, II, and III disease carry MSTs of 17-18 months, 5-6 months, and 3 months, respectively [12,13]. The survival times following palliative radiation therapy (RT) also varies from 5.3 to 11.9 months $[10,14-17]$, with a longer survival time of 11.9 months reported with concurrent cisplatin or carboplatin administration along with radiation therapy [17]. Systemic treatments such as immunotherapy and chemotherapy have been studied; chemother- 
apy for OMM has not been promising and immunotherapy, mainly the Oncept ${ }^{\circledR}$ vaccine, shows varying results $[8,9,18,19]$. With limited treatment options and short survival times, OMM truly is a devastating cancer. A retrospective study reported that $32 \%$ of dogs with melanocytic neoplasm were alive at follow-up or died of causes unrelated to the neoplasm and concluded that not all melanocytic oral neoplasm should be considered highly malignant [20]. A variant of OMM, known as histologically well-differentiated melanocytic neoplasm (HWDMN), with a low mitotic index (MI < 4 per $10 \mathrm{hpf})$, has a more favorable prognosis compared to traditional OMM [21]. Patients with HWDMN have been reported to have prolonged MST with local surgical excision only [21]. An MST of 34 months has been reported in patients with HWDMN in the literature, with a low recurrence rate of $3.1 \%$ [21]. Two other variants of OMM, balloon cell melanoma and signet ring melanoma, have been reported in two histopathologic studies; however, the clinical ramifications are unknown, as survival times were not reported [22,23]. The purpose of this review is to shed light on the lesser-known variant and to provide better understanding of this disease compared to the more common aggressive variant of malignant melanoma in the oral cavity of dogs.

\section{Signalment and Presenting Signs}

OMM is reported to be a disease that affects geriatric dogs. The mean age of those affected varies between 9-11.4 years of age [13,24], depending on the source, and can be seen in dogs from 1-17 years of age. Similarly, HWDMN has been reported in dogs between 3-17 years of age with a mean of 10.5 years [21].

There is contradicting information regarding gender prevalence for OMM. RamosVara reported no difference in OMM prevalence between the genders, while other studies indicate a higher prevalence in male dogs [24-26], similar to human literature where males are more affected compared to females, with male to female ratios of up to 2-1 reported in some cases [27-30]. Certain breeds have been noted to be predisposed to developing OMM. Cocker Spaniels, Poodles, Pekinese, Gordon Setter, Chow Chow, Golden Retrievers, mixed-breed dogs, and Dachshunds are reported to be the most common breeds affected by OMM [24,31]. HWDMNs have similarly been reported in Golden Retrievers, Labrador Retrievers, Doberman Pinscher, Irish Setters, Cocker Spaniels, Beagles, and mixed-breed dogs [21].

Presenting clinical signs of canine OMM can include bleeding, ptyalism, dysphagia, halitosis, and occasionally, mandibular fracture [3,4,32]. OMM can appear as multiple small brown-to-black masses, but also may be a large, irregular or flat mass, with varying level of pigmentation [33]. Similarly, dogs with HWDMN may present with pigmented, discrete to large lesions on the lips and within the oral cavity (Figure 1). Interestingly, in humans, OMM was reported in individuals of varying ages ranging from 22-83 years of age and a mean age of 56 years [34]. The incidence of prepubertal children with OMM is exceedingly uncommon [35]. The ethnic groups most affected by OMM are Japanese, black Africans, Native Americans, and Hispanics [36].
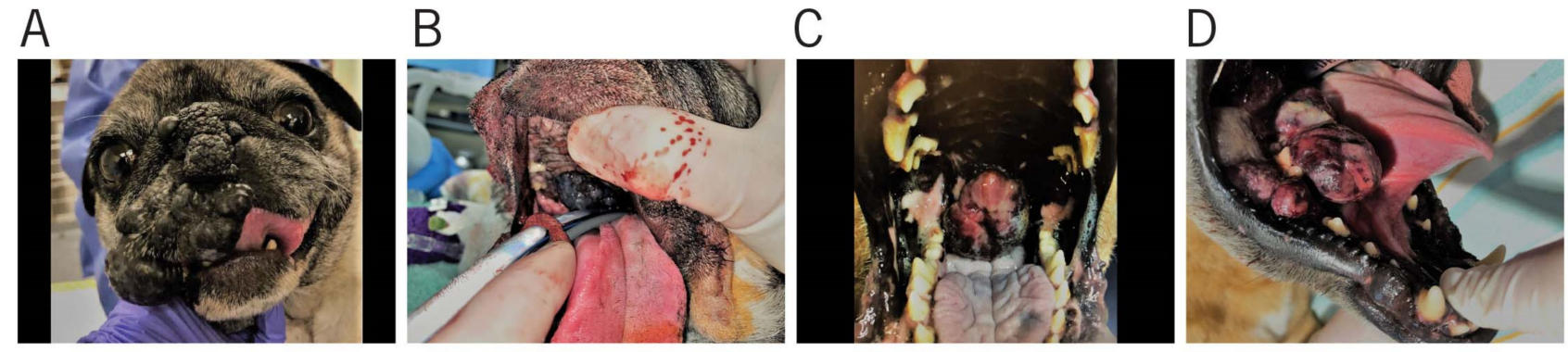

Figure 1. Similar clinical presentation of histologically confirmed histologically well-differentiated melanocytic neoplasm (HWDMN) and oral malignant melanoma (OMM): (A) Right rostral muzzle and nasal planum pigmented HDWMN obliterating normal anatomy; (B) Pigmented HWDMN of the hard palate extending into the soft palate; (C) Variably pigmented proliferative OMM of the soft palate; (D) Variably pigmented proliferative OMM of the right caudal mandible. 


\section{Gross Appearance and Cytology}

Grossly, OMM can vary in its appearance, with colors ranging from gray to red, and even dark blue [3]. Pigmentation does not provide a diagnosis of melanoma, as other neoplastic and nonneoplastic lesions can appear similar. The presence of melanin within the tumor can indicate melanoma; however, approximately one third of all melanoma cases in dogs are amelanotic malignant melanomas [13,24]. Furthermore, amelanotic malignant melanomas may grossly resemble sarcomas, lymphomas, carcinomas, and osteogenic tumors [3].

An initial diagnosis of melanoma can be achieved by cytologic assessment of the lesion as a screening measure, followed by histopathologic evaluation [3]. Cytologically, malignant melanoma has significant anisocytosis and anisokaryosis, hyperchromasia, abnormal chromatin clumping, one or more nucleoli, and atypical mitotic figures. These cells can be typed as epithelioid, round, spindle, or a mixture of these $[3,20]$. OMM cannot be differentiated from HWDMN based on cytology alone, as the cell population and appearance are similar. It can also be difficult to obtain a definitive diagnosis in cases of amelanotic and poorly differentiated melanomas, and immunohistochemistry using monoclonal and polyclonal antibodies is commonly employed to obtain a definitive diagnosis [3].

\section{Staging Diagnostics}

For dogs with OMM, the size of the primary tumor is reported to be prognostic [12]. Staging of canine OMM is based on the WHO TNM grading scheme (Table 1). Stage I diseases are those with tumors $<2 \mathrm{~cm}$ diameter, stage II tumors are $2 \mathrm{~cm}$ to $<4 \mathrm{~cm}$ diameter, and stage III tumors are $4 \mathrm{~cm}$ or greater and/or metastasized to the regional lymph node. Those with distant metastatic disease are considered stage IV. A similar staging system has not been reported for HWDMN.

Table 1. Adapted from World Health Organization (WHO) primary tumor, regional lymph node, metastasis (TNM) staging scheme for dogs with oral malignant melanoma (OMM) [11].

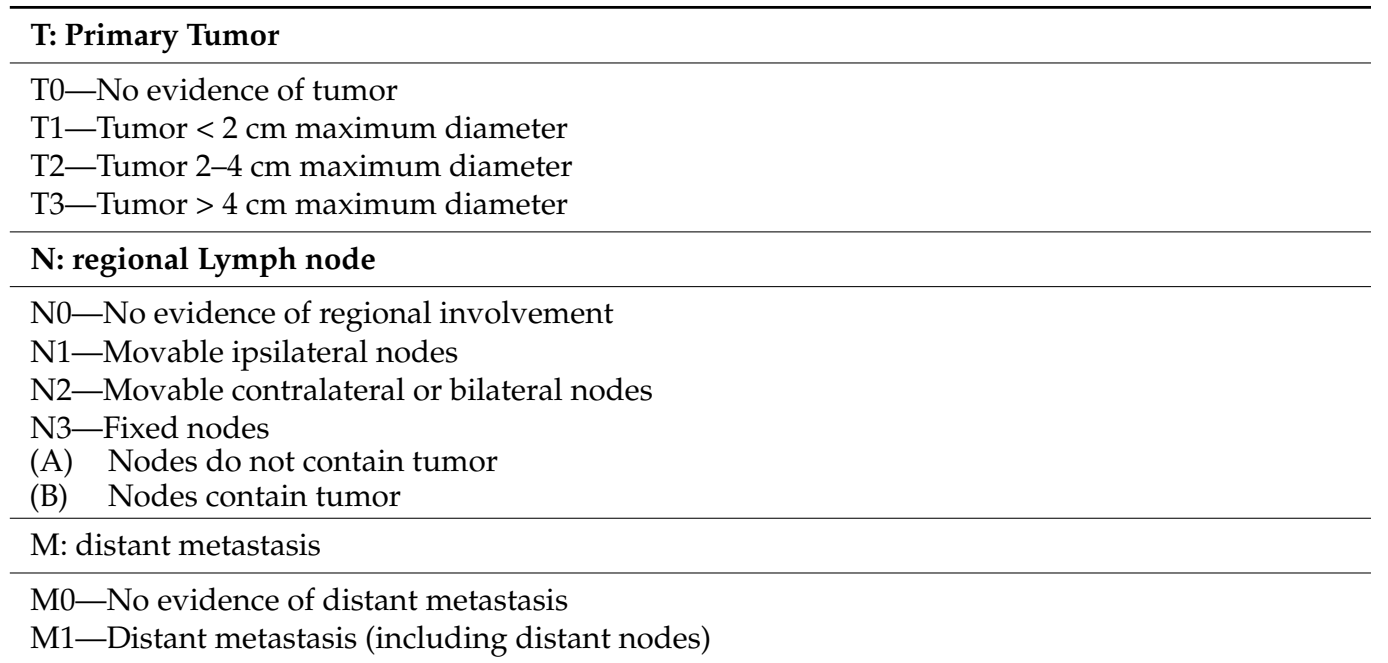

Stage grouping

Stage I-T1 N0 M0

Stage II-T2 N0 M0

Stage III-T2 N1 M0 or T3 N0 M0

Stage IV-Any T, any N and M1

Note. Adapted from TNM Classification of Tumours in Domestic Animals (1 st ed., p 23) by L.N. Owen, 1980, WHO.

A minimum database for staging includes a detailed history, physical exam, baseline bloodwork, urinalysis, chest radiographs, abdominal ultrasound, and local lymph node aspiration [12]. While HWDMN has a lower metastatic potential, staging diagnostics 
remain largely the same. All four lymph centers (ipsilateral and contralateral mandibular and medial retropharyngeal) should be aspirated for OMM. It is well known that lymph node size is not a reliable gauge of metastasis $[37,38]$ and fine needle aspirate is reported to have a $100 \%$ sensitivity and $96 \%$ specificity when detecting lymphatic metastasis of solid tumors [38]. In addition, it was reported that 33\% of patients with OMM had lymphatic metastasis to all four lymph centers, and $42 \%$ of patients had metastasis to the contralateral side [39]. Computed tomography (CT) imaging of the head and chest can be performed for staging and surgery planning [6].

\section{Histopathology}

As stated previously, the staging of canine OMM traditionally has been based on the WHO TMN classification system [11], which does not take into account the mitotic index (MI). MI refers to the percentage of cells in a population that are actively undergoing mitosis. A study by Hanh et al. noted that the WHO classification did not meet the objectives of tumor staging, which is to determine the extent of disease and to aid in recommending an effective treatment plan [40]. Their proposed alternative staging system was based on location, size, and the mitotic index of tumors, with better prognostic predictability. Their proposition was further corroborated by a recent study that found that large and nonpigmented tumors, necrosis, ulceration, high MI, and p53 expression are poor prognostic indicators [3]. Mitotic index is one of the most important criteria in differentiating HWDMN from OMM.

Histopathologically, OMM can be composed of cell types ranging from epithelioid, spindle, mixed, dendritic, and signet, with epithelioid cells reported to be the most common in one study [20] (Figure 2). A different study reported mixed cell types as the most common [24]. An important feature of OMM is junctional or intraepithelial tumor growth. It is common to see single atypical cells or cell nests with infiltration of the surface epithelial basal layer with anaplasia, varying levels of mitotic activity, and cell pleomorphism. In addition, invasion into the lymphatics and small veins is frequently seen [41]. The cells in the nests may be heavily pigmented, but there may be variations in the degree of pigmentation, with some that have no visible pigment [42]. It is reported that a third of canine melanomas are amelanotic [13].
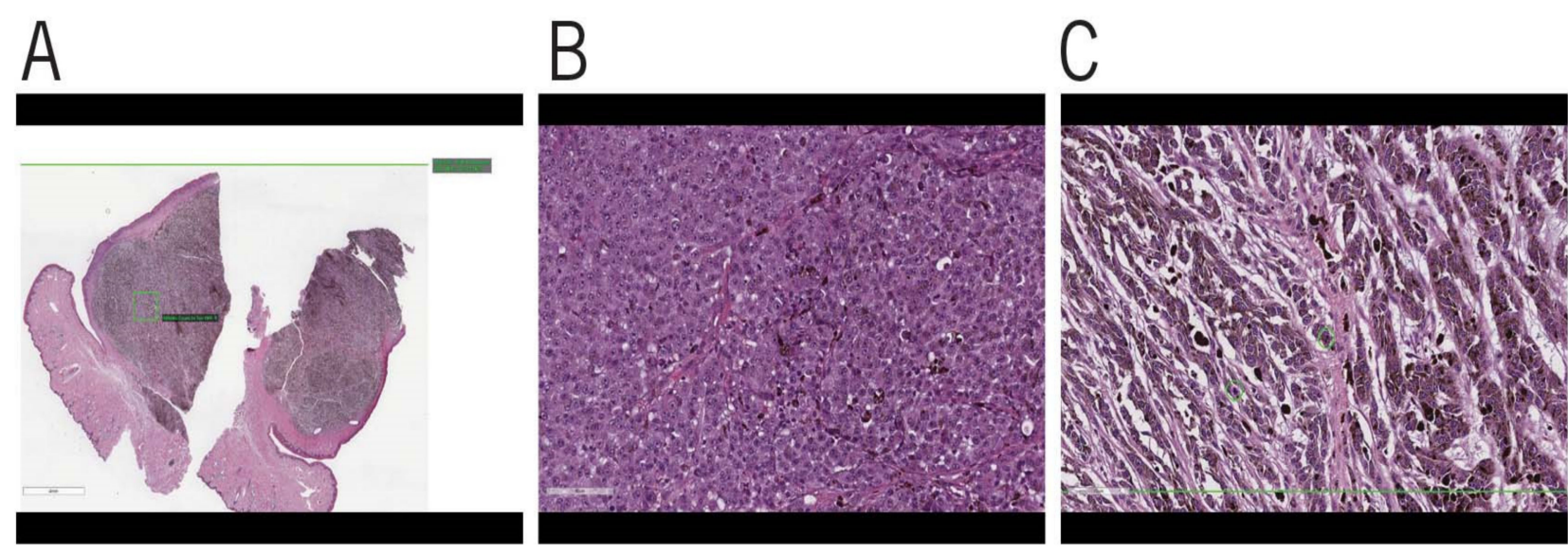

Figure 2. Histopathologic features of OMM: (A) Low magnification, bar $=4 \mathrm{~mm}$. Lightly pigmented mass beneath mucous membrane. Mitotic count of 9 per 10 high powered fields $\left(2.37 \mathrm{~mm}^{2}\right)$. The area framed by the green lines denotes the area assessed by the artificial intelligence (AI) software used by Antech diagnostics to calculate mitotic index (MI) in addition to manual counts done by the pathologists in the same field as a cross-check. The green circles indicate a location where mitotic figures were noted by the AI system. (B) Moderate magnification, bar $=90 \mathrm{um}$. Poorly pigmented tumor cells with moderate to marked nuclear atypia, large prominent nucleoli, and numerous mitotic figures. (C) High magnification, bar $=70 \mathrm{um}$. Lightly pigmented tumor cells with mildly pleomorphic oval nuclei and prominent nucleoli. Green circle indicates a location where mitotic figures were found by the AI software used by Antech diagnostics to calculate MI. 
In contrast, in HWDMNs, the neoplastic cells appear uniform in size and are either round or elongated. The nuclei in these cells are small and have a round to elongated appearance. The mitotic index of these neoplasms was reported to be low, with less than 4 per 10 hpf [21] (Figure 3).
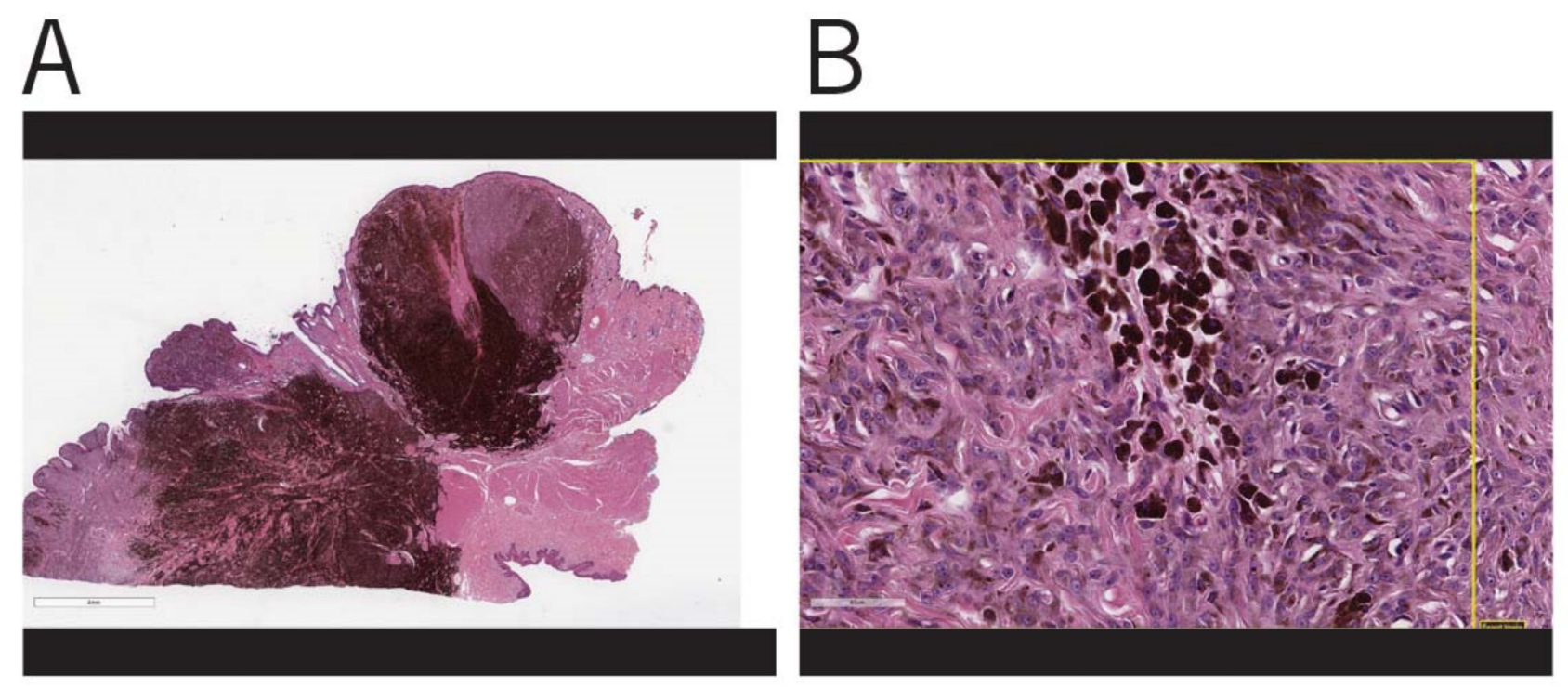

Figure 3. Histopathologic features of HWDMN: (A) Heavily pigmented pedunculated mass at mucocutaneous junction with early submucosal extension. Bar $=4 \mathrm{~mm}$; (B) Areas of heavily pigmented tumor cells adjacent to less pigmented tumor cells. Nuclei are mildly pleomorphic, oval and have prominent nucleoli, but no mitotic figures. The area framed by the yellow lines denotes the area assessed by the artificial intelligence (AI) software used by Antech diagnostics to calculate MI in addition to manual counts done by the pathologists in the same field as a cross-check. Bar $=60 \mathrm{um}$.

Immunohistochemistry (IHC) is the gold standard for the diagnosis of tumors of melanocytic derivation if a diagnosis is not possible on a standard hematoxylin and eosin (H\&E) prep. The distinguishing characteristic between an OMM and HWDMN is the low mitotic index of less than 4 per 10hpf and the well-differentiated appearance of the cells [21]. Thus, an examination of the cytomorphologic appearance in addition to IHC analysis may be important. It is imperative that clinicians are vigilant in their review of the microscopic findings in histopathology reports to determine whether HWDMN is a possible differential based on the differentiation of the cells and MI. Clinicians should be aware that the histopathologic diagnosis for both OMM and HWDMN will be malignant melanoma. Differentiating between the two diagnoses drastically changes prognosis with treatment for the patient and may affect an owner's decision on whether or not to pursue treatment.

With regards to IHCs, most melanomas, including HWDMN, are cytokeratin negative and vimentin positive [3], but sarcomas can have similar staining patterns [43]. Other monoclonal antibodies $(\mathrm{mAb})$ are available to aid in the detection of melanoma in humans and dogs [44]. Markers, including vimentin, S-100 protein, neuron-specific enolase (NSE), Melan A, PNL2, human melanosome-specific antigens -1 (HMSA-1), and HMSA-5 have been assessed for their potential in aiding the diagnosis of canine malignant melanoma.

In a study by Ramos et al. it was reported that $100 \%$ of melanomas were positive for vimentin. The authors concluded that although vimentin is a sensitive marker for mesenchymal cells, due to its low specificity, it should considered a preliminary screening tool [24]. S-100 protein is an intracellular and intranuclear acidic, calcium-binding protein [45], commonly found in melanocytic lesion. However, this protein is also found in other nonmelanocytic cells, including Langerhans cells, macrophages, chondrocytes, neurons, and others $[24,46]$. Approximately $76-84 \%$ of canine melanoma tumors were positive for S-100 protein [24,47]. NSE is found in peripheral and central neuroendocrine cells, neurons, and melanocytes, and tumors derived from these cells [46]. Although this 
protein is not very specific for melanomas, $89.1 \%$ of melanomas were positive for this protein in one study [24]. Positive immunoreactivity for vimentin, S-100 and NSE along with a negative cytokeratin immunoreactivity supports a melanoma diagnosis [44]. Melan A is a protein that elicits a cytotoxic T-cell response and is considered the most specific IHC test used due to its narrow tissue distribution [3]. Ramos-Vara et al. reported that of the 122 canine oral melanomas and 7 metastatic melanomas, $92 \%$ were Melan A positive, $100 \%$ vimentin positive, $76 \%$ S100 positive, and $89.1 \%$ NSE positive [24]. As 32\% of the total number of tumors were nonpigmented; the assumption is that a significant proportion of amelanotic melanocyte tumors were reactive to Melan A. In the same study, a large population of non-melanocytic tumors (not amelanotic melanomas) were tested for Melan A, with only four tumors reacting to the protein. These findings led to the conclusion that Melan A is a sensitive and specific marker for melanocytic neoplasms [24]. PNL2 is a monoclonal antibody that targets fixative resistant melanocytic antigen and was developed for human melanoma diagnosis [48]. The antigen targeted by PNL2 is reported to be detectable even after melanin bleaching and decalcification, adding to PNL2's value in diagnosing malignant melanoma [48]. Furthermore, PNL2 has a higher sensitivity compared to Melan-A and lacks cross-reactivity with nonmelanocytic neoplasms [49]. PNL2 is a reliable marker in the identification of canine melanomas, with close to $100 \%$ sensitivity when used together with Melan A and tyrosinase [49].

In human medicine, the development of murine antibodies targeting melanomaassociated antigens, such as melanosome [50], has further solidified the value of IHC in diagnosing melanoma [3]. mAb used in human medicine for diagnosis of melanomas that cross-react with canine melanomas include human melanosome-specific antigens-1 (HMSA-1), HMSA-5, and Melan A [44,50]. HMSA-1 and HMSA-5 individually are reported to react with $60 \%$ and $69 \%$ of canine melanomas, respectively. However, when used together, they react with $83 \%$ of canine melanomas [3].

IBF9 is the only known murine $\mathrm{mAb}$ generated specifically for canine melanoma detection $[3,51]$. IBF reacted positively to only $63 \%$ of melanomas tested and reacted to $30 \%$ of non-melanocytic tumors such as cutaneous lymphoma and basal cell tumors [51]. IBF9 can cross-react with other tumors, but additional antibody IHC testing and cytomorphologic examination can make IBF9 more useful [3]. Similarly, using multiple antibodies can help to increase diagnostic accuracy. A cost-effective and efficient immunodiagnostic cocktail, containing PLN2, Melan-A, TRP-1, and TRP-2, has been found to be effective, with 93.9\% sensitivity and $100 \%$ specificity in canine amelanotic melanocytic lesions [52].

A study in humans assessed the immunohistochemical expression of different tumorsuppressive genes including, $\mathrm{p} 53, \mathrm{p} 16, \mathrm{Rb}$, and $\mathrm{pRb} 2 / \mathrm{p} 130$ proteins. This study revealed that $\mathrm{p} 53$ expression was associated with poor prognosis, while the expression of $\mathrm{pRb} / \mathrm{p} 130$ proteins were associated with a higher survival rate [53]. To the author's knowledge thus far, evaluation of these suppressive genes has not yet been assessed in veterinary medicine but could be of great value in the treatment of OMM in veterinary patients, as it may help elucidate the subset of patients that may fare better with treatment. Further studies examining the correlation between these genes and stage of OMM in veterinary patients is required.

\section{Treatment}

Surgery is the most effective treatment for the elimination of the primary tumor [8]. Prior to surgery, computed tomography (CT) is commonly utilized for the staging of OMM and treatment planning [6]. Because of OMM's propensity to metastasize, systemic treatment should ideally be a consideration. However, despite this recommendation, no significant improvement in survival times have been noted in multiple protocols that have been investigated $[8,13,18,54]$. Tuohy et al. found that surgery with adjuvant therapy did not improve the survival times in patients with OMM [8]. Rather, patients that received adjuvant therapy had a shorter mean survival time (MST) of 396 days compared to 874 days for dogs that had surgery only. The adjuvant therapies for this study included different 
combinations of maximum tolerated chemotherapy, metronomic chemotherapy, radiation therapy, and a melanoma vaccine. In a study by Boston et al., patients treated with surgery alone versus surgery followed by systemic adjuvant, had an MST of 355 days and 352 days, respectively [18]. Adjuvant therapies in this study included hypofractionated radiation therapy, chemotherapy, metronomic chemotherapy, and melanoma vaccination. In the case of HWDMNs, however, Esplin noted that patients treated only with local excision had an MST of 34 months, with extremely low recurrence rates and low metastatic potential-with only 2 of the 64 dogs having suspected metastasis [21]. Thus, wide-margin surgery may be sufficient for HWDMNs as the sole treatment, due to a low recurrence rate and low potential for metastasis.

Radiation therapy (RT) may be useful for the control of local disease in certain cases. A few studies have noted that chemotherapeutics in conjunction with radiation therapy (not surgery) was successful in prolonging the median time to progression and survival time $[17,55]$. Historically thought of as radio-insensitive, many studies now suggest radiation therapy as a reasonable option for OMM, especially if the tumors are smaller. Proulx et al. found that dogs without bony destruction had longer disease-free intervals and overall survival compared to those with bone invasion after RT [14]. The response rates to RT ranged from $82-94 \%$ and an MST of 5.3-11.9 months [14,16,17,33,55,56], with the longer survival times reported with concurrent carboplatin or cisplatin administration in some studies [17]. In a study by Cancedda et al., the authors noted increased time to progression, with median of 205 days for those that received RT and temozolomide, compared to 110 days for those that received RT only, though survival times were not significantly different [55]. It is possible that a subset of OMM that have responded well to radiation therapy and surgery were dogs with HWDMN, as the mitotic index in most of the current published studies was not assessed. To the authors' knowledge, efficacy and outcome information with RT in dogs with HWDMNs has not been reported.

Efficacy of numerous chemotherapeutics has been studied in both human and veterinary medicine. Treatments with carboplatin, cisplatin, and melphalan have been assessed in multiple veterinary studies, but have not shown improvement in the overall survival time and showed low response rates. Multiple studies evaluating different chemotherapies as the sole treatment $[57,58]$ and as an adjuvant treatment following surgery [54,59] or radiation therapy $[14,16]$ report underwhelming results. Similarly, in humans, the role of chemotherapy remains unclear, with multiple studies reporting response rates as low as $10 \%$ and a general lack of efficacy in this disease [60-64].

Immunotherapy for the treatment of canine OMM is an area of active research and development. The goal of immunotherapy is to activate the immune system to modulate the progression and spread of melanoma. A variety of biological agents have been examined for their potential to elicit an antitumor response by the immune system. Bacillus Calmette-Guerin (BCG), IFN-alpha, IL-2m and immunization activators have shown promise [65]. A xenogenic DNA-encoding tyrosinase protein vaccine, the Oncept ${ }^{\circledR}$ vaccine, has been available since 2007, and has been reported to be well-tolerated, with minimal side effects $[9,19,66]$. While initial prospective studies showed improvements in survival times when used as an adjuvant $[19,66]$, the more recent retrospective studies have reported equivocal benefits of the melanoma vaccine in terms of the progression-free survival, disease-free interval, and MST compared to patients who did not receive the vaccine in an adjuvant manner $[8,18,67]$.

In humans, an area of intense research is the development of therapies to improve immune-mediated destruction of neoplastic cells [13]. T-cell mediated cytotoxicity was found to be impaired when T-cell programmed-death-receptor-1(PD-1) and programmed death receptor ligand (PD-L1), expressed by antigen-presenting cells and cancer cells, interact and lead to downregulation of T-cell activation. Melanoma has been shown to express PD-L1 on the cell surface [68]. This disruption in immunity allows for the tumor to evade the immune system and continue to grow [64]. One strategy that is under investigation is the inhibition of PD-L1 and PD-1 interaction, thereby keeping the T-cell 
mediated response intact. One example of this is the pembrolizumab, which is an antibody against PD-1. The drug underwent phase 1 trial, with promising results in 2014; 88\% of responses to the drug were ongoing at median follow-up of 8 months [68]. This is consistent with previous findings where immunotherapies were noted to have long-lasting clinical benefit $[69,70]$. Pembrolizumab was approved for treatment of recurrent or metastatic cervical cancer by the Food and Drug Administration on 13 October 2021. These results provide some hope for systemic treatments of OMM. Research into the feasibility of this therapy in veterinary patients is needed.

\title{
7. Prognosis
}

Dogs with OMM historically have poor prognosis, with untreated oral melanoma patients having an MST of 65 days [7]. MSTs for stages I, II, and III are 17-18 months, 5-6 months, and 3 months following surgery, respectively [71]. As stated previously, a melanoma vaccine and RT with concurrent chemotherapy may improve survival times based on some studies. In contrast, patients with HWDMN have a prolonged MST of 34 months and a recurrence rate of $3.1 \%$.

\section{Conclusions}

There is a lot of information in the veterinary literature regarding OMM. The one commonality amongst the studies is that OMM is a devastating disease with aggressive local disease and high propensity for spread. Prognosis is poor, with most patients succumbing to disease progression even in the face of aggressive surgery, and with adjuvant treatments having questionable efficacy in improving outcome. However, a variant of OMM known as HWDMN has a different biological behavior that affords patients longer survival times. As such, it is important to recognize that despite OMM diagnosis, a review of the histopathologic characteristic of the tumor is crucial, as it may yield a more favorable prognosis. The authors strongly recommend reviewing the pathologist's findings and comments to ensure HWDMN is not missed, as this diagnosis could provide a more accurate prognosis and determine a proper treatment plan.

Author Contributions: W.S.K. and A.V. drafted the manuscript, B.P. provided histopathology images and revised the manuscript. All authors have read and agreed to the published version of the manuscript.

Funding: This research received no external funding.

Institutional Review Board Statement: Not applicable.

Informed Consent Statement: Not applicable.

Data Availability Statement: Not applicable.

Acknowledgments: The authors would like to thank Andrea Wood for assistance with image formatting and Beatrix Jenei for supplying photos of canine melanomas.

Conflicts of Interest: The authors declare no conflict of interest.

\author{
Abbreviations \\ OMM Oral Malignant Melanoma \\ HWDMN Histologically Well-Differentiated Melanocytic Neoplasm \\ MST Median Survival Time \\ IMRT Intensity-Modulated Radiation Therapy \\ RT Radiation Therapy \\ WHO World Health Organization
}




\section{References}

1. Mikiewicz, M.; Paździor-Czapula, K.; Gesek, M.; Lemishevskyi, V.; Otrocka-Domagała, I. Canine and Feline Oral Cavity Tumours and Tumour-like Lesions: A Retrospective Study of 486 Cases (2015-2017). J. Comp. Pathol. 2019, 172, 80-87. [CrossRef] [PubMed]

2. Sarowitz, B.N.; Davis, G.J.; Kim, S. Outcome and prognostic factors following curative-intent surgery for oral tumours in dogs: 234 cases (2004 to 2014). J. Small Anim. Pract. 2017, 58, 146-153. [CrossRef] [PubMed]

3. Smith, S.H.; Goldschmidt, M.; McManus, P.M. A comparative review of melanocytic neoplasms. Vet. Pathol. 2002, 39, 651-678. [CrossRef] [PubMed]

4. Brodey, R.S. The biological behaviour of canine oral and pharyngeal neoplasms. J. Small Anim. Pract. 1970, 11, 45-53. [CrossRef]

5. Harvey, H.J. Oral tumors. Vet. Clin. N. Am. Small Anim. Pract. 1985, 15, 493-500. [CrossRef]

6. Willcox, J.L.; Spriet, M.; Zwingenberger, A.L.; Phillips, K.L.; Burton, J.H.; Skorupski, K.A.; Hansen, K.S.; Affolter, V.K.; Woolard, K.D.; Beylin, D.; et al. Evaluation of accuracy for (18) F-FDG positron emission tomography and computed tomography for detection of lymph node metastasis in canine oral malignant melanoma. Vet. Comp. Oncol. 2021, 19, 463-472. [CrossRef]

7. Harvey, H.J.; MacEwen, E.G.; Braun, D.; Patnaik, A.K.; Withrow, S.J.; Jongeward, S. Prognostic criteria for dogs with oral melanoma. J. Am. Vet. Med. Assoc. 1981, 178, 580-582. [PubMed]

8. Tuohy, J.L.; Selmic, L.E.; Worley, D.R.; Ehrhart, N.P.; Withrow, S.J. Outcome following curative-intent surgery for oral melanoma in dogs: 70 cases (1998-2011). J. Am. Vet. Med. Assoc. 2014, 245, 1266-1273. [CrossRef] [PubMed]

9. Bergman, P.J.; Camps-Palau, M.A.; McKnight, J.A.; Leibman, N.F.; Craft, D.M.; Leung, C.; Liao, J.; Riviere, I.; Sadelain, M.; Hohenhaus, A.E.; et al. Development of a xenogeneic DNA vaccine program for canine malignant melanoma at the Animal Medical Center. Vaccine 2006, 24, 4582-4585. [CrossRef] [PubMed]

10. Bateman, K.E.; Catton, P.A.; Pennock, P.W.; Kruth, S.A. 0-7-21 radiation therapy for the treatment of canine oral melanoma. J. Vet. Intern. Med. 1994, 8, 267-272. [CrossRef] [PubMed]

11. World Health Organization. TNM Classification of Tumours in Domestic Animals; Owen, L.N., Ed.; World Health Organization: Geneva, Switzerland, 1980.

12. Bergman, P.J. Canine Oral Melanoma. Clin. Tech. Small Anim. Pract. 2007, 22, 55-60. [CrossRef]

13. Nishiya, A.T.; Massoco, C.O.; Felizzola, C.R.; Perlmann, E.; Batschinski, K.; Tedardi, M.V.; Garcia, J.S.; Mendonça, P.P.; Teixeira, T.F.; Zaidan Dagli, M.L. Comparative Aspects of Canine Melanoma. Vet. Sci. 2016, 3, 7. [CrossRef] [PubMed]

14. Proulx, D.R.; Ruslander, D.M.; Dodge, R.K.; Hauck, M.L.; Williams, L.E.; Horn, B.; Price, G.S.; Thrall, D.E. A retrospective analysis of 140 dogs with oral melanoma treated with external beam radiation. Vet. Radiol. Ultrasound 2003, 44, 352-359. [CrossRef] [PubMed]

15. Théon, A.P.; Rodriguez, C.; Madewell, B.R. Analysis of prognostic factors and patterns of failure in dogs with malignant oral tumors treated with megavoltage irradiation. J. Am. Vet. Med. Assoc. 1997, 210, 778-784. [PubMed]

16. Murphy, S.; Hayes, A.M.; Blackwood, L.; Maglennon, G.; Pattinson, H.; Sparkes, A.H. Oral malignant melanoma-the effect of coarse fractionation radiotherapy alone or with adjuvant carboplatin therapy. Vet. Comp. Oncol. 2005, 3, 222-229. [CrossRef]

17. Freeman, K.P.; Hahn, K.A.; Harris, F.D.; King, G.K. Treatment of dogs with oral melanoma by hypofractionated radiation therapy and platinum-based chemotherapy (1987-1997). J. Vet. Intern. Med. 2003, 17, 96-101. [PubMed]

18. Boston, S.E.; Lu, X.; Culp, W.T.; Montinaro, V.; Romanelli, G.; Dudley, R.M.; Liptak, J.M.; Mestrinho, L.A.; Buracco, P. Efficacy of systemic adjuvant therapies administered to dogs after excision of oral malignant melanomas: 151 cases (2001-2012). J. Am. Vet. Med. Assoc. 2014, 245, 401-407. [CrossRef] [PubMed]

19. Grosenbaugh, D.A.; Leard, A.T.; Bergman, P.J.; Klein, M.K.; Meleo, K.; Susaneck, S.; Hess, P.R.; Jankowski, M.K.; Jones, P.D.; Leibman, N.F.; et al. Safety and efficacy of a xenogeneic DNA vaccine encoding for human tyrosinase as adjunctive treatment for oral malignant melanoma in dogs following surgical excision of the primary tumor. Am. J. Vet. Res. 2011, 72, 1631-1638. [CrossRef] [PubMed]

20. Spangler, W.L.; Kass, P.H. The histologic and epidemiologic bases for prognostic considerations in canine melanocytic neoplasia. Vet. Pathol. 2006, 43, 136-149. [CrossRef] [PubMed]

21. Esplin, D.G. Survival of dogs following surgical excision of histologically well-differentiated melanocytic neoplasms of the mucous membranes of the lips and oral cavity. Vet. Pathol. 2008, 45, 889-896. [CrossRef] [PubMed]

22. Cangul, I.T.; van Garderen, E.; van der Linde-Sipman, J.S.; van den Ingh, T.S.; Schalken, J.A. Canine balloon and signet-ring cell melanomas: A histological and immunohistochemical characterization. J. Comp. Pathol. 2001, 125, 166-173. [CrossRef]

23. Blanchard, T.; Bryant, N.; Mense, M. Balloon cell melanoma in three dogs: A histopathological, immunohistochemical and ultrastructural study. J. Comp. Pathol. 2001, 125, 254-261. [CrossRef] [PubMed]

24. Ramos-Vara, J.A.; Beissenherz, M.E.; Miller, M.A.; Johnson, G.C.; Pace, L.W.; Fard, A.; Kottler, S.J. Retrospective study of 338 canine oral melanomas with clinical, histologic, and immunohistochemical review of 129 cases. Vet. Pathol. 2000, 37, 597-608. [CrossRef] [PubMed]

25. Todoroff, R.J.; Brodey, R.S. Oral and pharyngeal neoplasia in the dog: A retrospective survey of 361 cases. J. Am. Vet. Med. Assoc. 1979, 175, 567-571.

26. Miller, W.H., Jr.; Griffin, C.E.; Campbell, K.L. Muller and Kirk's Small Animal Dermatology, 7th ed.; Elsevier Mosby: Saint Louis, MO, USA, 2013.

27. Aloua, R.; Kaouani, A.; Kerdoud, O.; Salissou, I.; Slimani, F. Melanoma of the oral cavity: A silent killer. Ann. Med. Surg. 2021, 62, 182-185. [CrossRef] [PubMed] 
28. Chae, Y.S.; Lee, J.Y.; Lee, J.W.; Park, J.Y.; Kim, S.M.; Lee, J.H. Survival of oral mucosal melanoma according to treatment, tumour resection margin, and metastases. Br. J. Oral Maxillofac. Surg. 2020, 58, 1097-1102. [CrossRef]

29. Van der Waal, R.I.; Snow, G.B.; Karim, A.B.; van der Waal, I. Primary malignant melanoma of the oral cavity: A review of eight cases. Br. Dent. J. 1994, 176, 185-188.

30. Patel, S.G.; Prasad, M.L.; Escrig, M.; Singh, B.; Shaha, A.R.; Kraus, D.H.; Boyle, J.O.; Huvos, A.G.; Busam, K.; Shah, J.P. Primary mucosal malignant melanoma of the head and neck. Head Neck 2002, 24, 247-257. [CrossRef]

31. Gillard, M.; Cadieu, E.; De Brito, C.; Abadie, J.; Vergier, B.; Devauchelle, P.; Degorce, F.; Dréano, S.; Primot, A.; Dorso, L.; et al. Naturally occurring melanomas in dogs as models for non-UV pathways of human melanomas. Pigment. Cell Melanoma Res. 2014, 27, 90-102. [CrossRef]

32. Goldschmidt, M.H. Benign and malignant melanocytic neoplasms of domestic animals. Am. J. Dermatopathol. 1985, 7, 203-212. [CrossRef]

33. Prouteau, A.; André, C. Canine Melanomas as Models for Human Melanomas: Clinical, Histological, and Genetic Comparison. Genes 2019, 10, 501. [CrossRef] [PubMed]

34. Hicks, M.J.; Flaitz, C.M. Oral mucosal melanoma: Epidemiology and pathobiology. Oral Oncol. 2000, 36, 152-169. [CrossRef]

35. Goubran, G.F.; O Adekeye, E.; Edwards, M.B. Melanoma of the face and mouth in Nigeria. A review and comment on three cases. Int. J. Oral Surg. 1978, 7, 453-462. [CrossRef]

36. Tremblay, J.-F.; O'Brien, E.A.; Chauvin, P.J. Melanoma In Situ of the oral mucosa in an adolescent with dysplastic nevus syndrome. J. Am. Acad. Dermatol. 2000, 42, 844-846. [CrossRef] [PubMed]

37. Williams, L.E.; Packer, R.A. Association between lymph node size and metastasis in dogs with oral malignant melanoma: 100 cases (1987-2001). J. Am. Vet. Med. Assoc. 2003, 222, 1234-1236. [CrossRef]

38. Langenbach, A.; McManus, P.M.; Hendrick, M.J.; Shofer, F.S.; Sorenmo, K.U. Sensitivity and specificity of methods of assessing the regional lymph nodes for evidence of metastasis in dogs and cats with solid tumors. J. Am. Vet. Med. Assoc. 2001, 218, 1424-1428. [CrossRef]

39. Skinner, O.T.; Boston, S.E.; Souza, C.H.D.M. Patterns of lymph node metastasis identified following bilateral mandibular and medial retropharyngeal lymphadenectomy in 31 dogs with malignancies of the head. Vet. Comp. Oncol. 2017, 15, 881-889. [CrossRef]

40. Hahn, K.A.; DeNicola, D.B.; Richardson, R.C.; Hahn, E.A. Canine oral malignant melanoma: Prognostic utility of an alternative staging system. J. Small Anim. Pract. 1994, 35, 251-256. [CrossRef]

41. Weiss, E.; Frese, K. Tumours of the skin. Bull. World Health Organ. 1974, 50, 79-100.

42. Head, K.W. Tumours of the upper alimentary tract. Bull. World Health Organ. 1976, 53, 145-166. [PubMed]

43. Rabanal, R.H.; Fondevila, D.M.; Montané, V.; Domingo, M.; Ferrer, L. Immunocytochemical diagnosis of skin tumours of the dog with special reference to undifferentiated types. Res. Vet. Sci. 1989, 47, 129-133. [CrossRef]

44. Sulaimon, S.; Kitchell, B.; Ehrhart, E. Immunohistochemical detection of melanoma-specific antigens in spontaneous canine melanoma. J. Comp. Pathol. 2002, 127, 162-168. [CrossRef] [PubMed]

45. Potts, B.C.; Smith, J.; Akke, M.; Macke, T.J.; Okazaki, K.; Hidaka, H.; Case, D.A.; Chazin, W.J. The structure of calcyclin reveals a novel homodimeric fold for S100 Ca(2+)-binding proteins. Nat. Struct. Biol. 1995, 2, 790-796. [CrossRef] [PubMed]

46. Ruiter, D.J.; Brocker, E.B. Immunohistochemistry in the evaluation of melanocytic tumors. Semin. Diagn. Pathol. 1993, 10, 76-91. [PubMed]

47. Sandusky, G.E., Jr.; Carlton, W.W.; Wightman, K.A. Immunohistochemical staining for S100 protein in the diagnosis of canine amelanotic melanoma. Vet. Pathol. 1985, 22, 577-581. [CrossRef] [PubMed]

48. Rochaix, P.; Lacroix-Triki, M.; Lamant, L.; Pichereaux, C.; Valmary, S.; Puente, E.; Al Saati, T.; Monsarrat, B.; Susini, C.; Buscail, L.; et al. PNL2, a new monoclonal antibody directed against a fixative-resistant melanocyte antigen. Mod. Pathol. 2003, 16, 481-490. [CrossRef]

49. Ramos-Vara, J.A.; Miller, M.A. Immunohistochemical identification of canine melanocytic neoplasms with antibodies to melanocytic antigen PNL2 and tyrosinase: Comparison with Melan A. Vet. Pathol. 2011, 48, 443-450. [CrossRef]

50. Berrington, A.J.; Jimbow, K.; Haines, D.M. Immunohistochemical detection of melanoma-associated antigens on formalin-fixed, paraffin-embedded canine tumors. Vet. Pathol. 1994, 31, 455-461. [CrossRef]

51. Oliver, J.L., 3rd; Wolfe, L.G. Antigen expression in canine tissues, recognized by a monoclonal antibody generated against canine melanoma cells. Am. J. Vet. Res. 1992, 53, 123-128.

52. Smedley, R.C.; Spangler, W.L.; Esplin, D.G.; Kitchell, B.E.; Bergman, P.J.; Ho, H.Y.; Bergin, I.L.; Kiupel, M. Prognostic markers for canine melanocytic neoplasms: A comparative review of the literature and goals for future investigation. Vet. Pathol. 2011, 48, 54-72. [CrossRef]

53. Tanaka, N.; Mimura, M.; Ichinose, S.; Odajima, T. Malignant melanoma in the oral region: Ultrastructural and immunohistochemical studies. Med. Electron. Microsc. 2001, 34, 198-205. [CrossRef]

54. Brockley, L.K.; Cooper, M.A.; Bennett, P.F. Malignant melanoma in 63 dogs (2001-2011): The effect of carboplatin chemotherapy on survival. N. Z. Vet. J. 2013, 61, 25-31. [CrossRef] [PubMed]

55. Cancedda, S.; Rohrer Bley, C.; Aresu, L.; Dacasto, M.; Leone, V.F.; Pizzoni, S.; Gracis, M.; Marconato, L. Efficacy and side effects of radiation therapy in comparison with radiation therapy and temozolomide in the treatment of measurable canine malignant melanoma. Vet. Comp. Oncol. 2016, 14, e146-e157. [CrossRef] [PubMed] 
56. Kawabe, M.; Mori, T.; Ito, Y.; Murakami, M.; Sakai, H.; Yanai, T.; Maruo, K. Outcomes of dogs undergoing radiotherapy for treatment of oral malignant melanoma: 111 cases (2006-2012). J. Am. Vet. Med. Assoc. 2015, 247, 1146-1153. [CrossRef] [PubMed]

57. Boria, P.A.; Murry, D.J.; Bennett, P.F.; Glickman, N.W.; Snyder, P.W.; Merkel, B.L.; Schlittler, D.L.; Mutsaers, A.J.; Thomas, R.M.; Knapp, D.W. Evaluation of cisplatin combined with piroxicam for the treatment of oral malignant melanoma and oral squamous cell carcinoma in dogs. J. Am. Vet. Med. Assoc. 2004, 224, 388-394. [CrossRef] [PubMed]

58. Rassnick, K.M.; Ruslander, D.M.; Cotter, S.M.; Al-Sarraf, R.; Bruyette, D.S.; Gamblin, R.M.; Meleo, K.A.; Moore, A.S. Use of carboplatin for treatment of dogs with malignant melanoma: 27 cases (1989-2000). J. Am. Vet. Med. Assoc. 2001, 218, 1444-1448. [CrossRef] [PubMed]

59. Dank, G.; Rassnick, K.M.; Sokolovsky, Y.; Garrett, L.D.; Post, G.S.; Kitchell, B.E.; Sellon, R.K.; Kleiter, M.; Northrup, N.; Segev, G. Use of adjuvant carboplatin for treatment of dogs with oral malignant melanoma following surgical excision. Vet. Comp. Oncol. 2014, 12, 78-84. [CrossRef] [PubMed]

60. Mihajlovic, M.; Vlajkovic, S.; Jovanovic, P.; Stefanovic, V. Primary mucosal melanomas: A comprehensive review. Int. J. Clin. Exp. Pathol. 2012, 5, 739-753. [PubMed]

61. Thompson, L.D.R.; Wieneke, J.A.; Miettinen, M. Sinonasal tract and nasopharyngeal melanomas: A clinicopathologic study of 115 cases with a proposed staging system. Am. J. Surg. Pathol. 2003, 27, 594-611. [CrossRef] [PubMed]

62. Lerner, B.A.; Stewart, L.A.; Horowitz, D.P.; Carvajal, R.D. Mucosal Melanoma: New Insights and Therapeutic Options for a Unique and Aggressive Disease. Oncology 2017, 31, e23-e32.

63. Shoushtari, A.N.; Bluth, M.J.; Goldman, D.A.; Bitas, C.; Lefkowitz, R.A.; Postow, M.A.; Munhoz, R.R.; Buchar, G.; Hester, R.H.; Romero, J.A.; et al. Clinical features and response to systemic therapy in a historical cohort of advanced or unresectable mucosal melanoma. Melanoma Res. 2017, 27, 57-64. [CrossRef] [PubMed]

64. Freeman-Keller, M.; Weber, J.S. Anti-programmed death receptor 1 immunotherapy in melanoma: Rationale, evidence and clinical potential. Ther. Adv. Med. Oncol. 2015, 7, 12-21. [CrossRef] [PubMed]

65. MacEwen, E.G.; Kurzman, I.D.; Vail, D.M.; Dubielzig, R.R.; Everlith, K.; Madewell, B.R.; Rodriguez, C.O.; Phillips, B., Jr.; Zwahlen, C.H.; Obradovich, J.; et al. Adjuvant therapy for melanoma in dogs: Results of randomized clinical trials using surgery, liposome-encapsulated muramyl tripeptide, and granulocyte macrophage colony-stimulating factor. Clin. Cancer Res. 1999, 5, $4249-4258$

66. Bergman, P.J.; McKnight, J.; Novosad, A.; Charney, S.; Farrelly, J.; Craft, D.; Wulderk, M.; Jeffers, Y.; Sadelain, M.; Hohenhaus, A.E.; et al. Long-term survival of dogs with advanced malignant melanoma after DNA vaccination with xenogeneic human tyrosinase: A phase I trial. Clin. Cancer Res. 2003, 9, 1284-1290. [PubMed]

67. Ottnod, J.M.; Smedley, R.C.; Walshaw, R.; Hauptman, J.G.; Kiupel, M.; Obradovich, J.E. A retrospective analysis of the efficacy of Oncept vaccine for the adjunct treatment of canine oral malignant melanoma. Vet. Comp. Oncol. 2013, 11, 219-229. [CrossRef]

68. Robert, C.; Ribas, A.; Wolchok, J.D.; Hodi, F.S.; Hamid, O.; Kefford, R.; Weber, J.S.; Joshua, A.M.; Hwu, W.J.; Gangadhar, T.C.; et al. Anti-programmed-death-receptor-1 treatment with pembrolizumab in ipilimumab-refractory advanced melanoma: A randomised dose-comparison cohort of a phase 1 trial. Lancet 2014, 384, 1109-1117. [CrossRef]

69. Topalian, S.L.; Sznol, M.; McDermott, D.F.; Kluger, H.M.; Carvajal, R.D.; Sharfman, W.H.; Brahmer, J.R.; Lawrence, D.P.; Atkins, M.B.; Powderly, J.D.; et al. Survival, durable tumor remission, and long-term safety in patients with advanced melanoma receiving nivolumab. J. Clin. Oncol. 2014, 32, 1020-1030. [CrossRef] [PubMed]

70. Hodi, F.S.; O’Day, S.J.; McDermott, D.F.; Weber, R.W.; Sosman, J.A.; Haanen, J.B.; Gonzalez, R.; Robert, C.; Schadendorf, D.; Hassel, J.C.; et al. Improved survival with ipilimumab in patients with metastatic melanoma. N. Engl. J. Med. 2010, 363, 711-723. [CrossRef]

71. MacEwen, E.G.; Patnaik, A.K.; Harvey, H.J.; Hayes, A.A.; Matus, R. Canine Oral Melanoma: Comparison of Surgery Versus Surgery Plus Corynebacterium parvum. Cancer Investig. 1986, 4, 397-402. [CrossRef] 